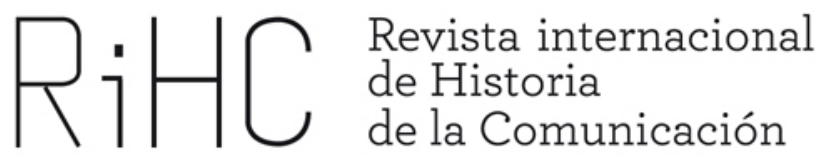

\title{
LA INFORMACIÓN AL SERVICIO DE LA POLÍTICA EXTERIOR. La creación de la oficina de información diplomática, respuesta del franquismo al aislamiento internacional (1945-1950)
}

DOI: http://dx.doi.org/10.12795/RiHC.2013.i01.07

Juan Manuel Fernández Fernández-Cuesta

Universidad Complutense de Madrid

imfer5@yahoo.es

Resumen: Al término de la Segunda Guerra Mundial, la diplomacia española fue excluida de los foros internacionales a pesar de sus esfuerzos neutralistas, iniciados a finales de 1942. El nuevo ministro de Asuntos Exteriores, Alberto Martin Artajo, un representante del sector católico que no era miembro del Cuerpo diplomático, realizó una profunda reforma de su departamento para organizar la réplica al aislamiento español. Con tal fin empleó la información y la propaganda como un instrumento al servicio de la política exterior. En este punto, su estrategia gravitó sobre dos polos: uno exterior, la embajada española en Washington; y otro interior, la Oficina de información Diplomática.

Palabras clave: política exterior española, Martín Artajo, información, propaganda. 
Abstract: After the Second World War, Spanish diplomacy was excluded from international forums in despite of its neutralist efforts at the end of 1942. The new Foreign Office Minister, Alberto Martín Artajo, a remarkable member from the Catholic faction who did not belong to Foreign Service, reformed in depth his department in order to organize the respond to Spanish isolation, which was focused on the use of information and propaganda as an instrument of the foreign policy. This diplomatic action gravitated on two poles: the Spanish Embassy in Washington and, indoors, the Diplomatic Information Office.

Keywords: Spanish foreign policy, Martín Artajo, information, propaganda. 
En los primeros días de 1946, año en el que la Organización de las Naciones Unidas aprobó, en su primera Asamblea General, el aislamiento del régimen de Franco, el gobierno emprendió una profunda reforma del ministerio de Asuntos Exteriores. Su nuevo titular era Alberto Martín Artajo, un reconocido representante del activismo católico, que, a sus 38 años, se convertía en la figura ascendente de la política española (Tusell, 1984, pp. 36-42 y Tusell, 1993, p.120).

En ese momento, el sistema político de Franco se enfrentaba a la batalla por su supervivencia. Las potencias ganadoras de la guerra mundial se mostraban dispuestas a acabar con la anomalía española a través de la exclusión de España de los nacientes foros internacionales. La réplica oficial del régimen se centró en el control de los medios de comunicación, ya sometidos a una férrea censura interna y ahora convertidos en vehículos de propaganda hacia el exterior. El ministerio de Asuntos Exteriores se hizo, progresivamente, con la iniciativa en este campo para llegar a ser "un actor de primera fila dentro del complicado teatro de la propaganda franquista" (Moreno, 2008, p. 55).

\section{Apuntes para un estado de la cuestión}

Nuestra investigación en torno al citado momento histórico parte de la obra de Javier Tusell, primero que tuvo acceso al fondo privado del ministro Martin Artajo y, poco después, al del ya tan influyente Luis Carrero Blanco, nombrado Subsecretario de la Presidencia en 1941. Parecía lógico iniciar nuestra aproximación a la cuestión con referencias, por breves que fueran, a sus estudios sobre el periodo, en los que la relación de la política exterior y los medios de comunicación cobra un especial protagonismo.

El estudio académico del aislamiento internacional de España en la etapa 1945-1950, viene siendo renovado permanentemente. Desde que a finales de los ochenta Florentino Portero defendió su tesis doctoral sobre la respuesta española al bloqueo no por casualidad, bajo la dirección del profesor Tusell-, que dio origen a su Franco, aislado (1989), hasta la actualidad, la cuestión, lejos de agotarse, ha seguido aportando datos para su revisión. Obras aparentemente definitivas, como los seis volúmenes de Lleonart (1978-2002) no han cerrado el tema. Al contrario, lo han abierto a nuevas perspectivas. Estudios posteriores (Portero y Pardo en 1996, Martínez Lillo, en 2000 y Pereira, en 2010) han reafirmado que los años de la "cuestión española", que llevaron a la retirada de los embajadores y al cierre de la frontera francesa, fueron vitales para el mantenimiento del sistema político del franquismo, tanto dentro como fuera de sus fronteras. 
En cuanto a la política interior, en esos años aparece con fuerza la pugna entre los sectores del franquismo (militares, falangistas, católicos y monárquicos), con repercusiones directas en la política informativa y en la acción exterior. La obra clásica de Payne sobre el régimen de Franco (1987) y su estudio sobre la evolución de la Falange dentro del nuevo Estado (1997) siguen siendo la base para cualquier investigación posterior. Destacan las realizadas por Lazo (1997 y 2008), Rodríguez Jiménez (2000), Cazorla (2000), Thomàs (2001), o Saz (2004), entre otros.

La investigación ha discurrido por diversos campos: el diplomático, el económico, el social... Y lo ha hecho también en el de los medios de comunicación, muy estudiados ya en la etapa del primer franquismo, con las aportaciones sobresalientes de Terrón (1981), Sinova (1989) o Barrera (1995). En estas obras se incidía en la restrictiva legislación periodística -desde la ley de 1938 a la de 1966-, con mención especial a la censura, las consignas, la depuración profesional o cualquier otro tipo de control. Ya en años más recientes, el enfoque ha girado hacia la influencia de los medios en la política exterior y su utilización desde el Estado como factor de propaganda. En esta nueva vía destacan las obras de Sevillano (1997 y 2002), Eiroa (2009), Moreno (2008, 2011 y 2012) y González Calleja (2011).

\section{El hombre del momento}

El nuevo ministro de Asuntos Exteriores, Alberto Martín Artajo, llegaba al departamento para sustituir al falangista José Félix de Lequerica, que sólo permaneció once meses en el puesto (entre agosto de 1944 y julio de 1945). Artajo se mantuvo al frente del ministerio durante doce años (1945-1957), marcando una época de la política española.

Martín Artajo actuó simultáneamente en dos niveles. Uno, propiamente diplomático, dirigiendo la respuesta del Gobierno para contrarrestar el aislamiento internacional al que había sido sometido el régimen; y otro, inserto en la política interior, encabezando el sector confesional del nuevo gabinete -el tercero de Franco, formado el 17 de julio de 1945-, en oposición a los falangistas, que empezaban a perder su control sobre los resortes fundamentales del poder, $y$, en especial, sobre la prensa.

Hasta entonces, la política informativa del ministerio de Exteriores había estado sujeta a las directrices de la Delegación Nacional de Prensa y Propaganda de Falange Española, que, aunque centrada en el control de los medios periodísticos españoles, nunca renunció a contrarrestar las "perniciosas campañas difusoras de doctrinas disolventes", especialmente las dirigidas por "agentes rusos al servicio de la revolución 
comunista" ${ }^{1}$. En los primeros años cuarenta, las escasas oficinas de Información de las Embajadas españolas recibían instrucciones desde instancias diversas. Las más frecuentes provenían de Exteriores, que formalmente se ocupaba de su coordinación, pero también les llegaban desde la citada Delegación Nacional o, incluso, del Servicio Nacional de la Falange Exterior ${ }^{2}$. La situación provocaba desconcierto y disputas, pues los campos de actuación no estaban claramente definidos entre la prensa dependiente del Estado y del partido. La pretendida fusión entre unos órganos y otros provocaba más bien la "con-fusión" (Dominguez Arribas, 2010), y en el plano ideológico impedía distinguir entre información y adoctrinamiento (Barrera, 1995, p. 32).

El acceso de Martín Artajo al Palacio de Santa Cruz convertirá a la información en un instrumento importante de la política exterior española. En ese periodo no se afrontarán acciones en el ámbito internacional sin el concurso de una política informativa que la respalde. En consecuencia, "los diplomáticos de Asuntos Exteriores formarán una diplomacia mediática de gran valor" (Eiroa, 2009, p. 304). El nuevo ministro se propuso reducir el poder de la censura falangista, no con la finalidad de liberalizar a la prensa en general sino de conseguir, antes que nada, que las publicaciones de la Iglesia no estuvieran sujetas a esa censura. En el campo de la prensa, el conflicto entre falangistas y católicos tuvo su origen en la propia guerra interna que sostenían entre sí los sectores de la Falange. De hecho, José Luis Arrese, al acceder a la Secretaría General del Movimiento en 1941, sustituyó a los colaboradores de Serrano Suñer, creó la Vicesecretaría de Educación Popular y puso a su frente a Gabriel Arias Salgado, de "identidad falangista más bien incierta y un católico del ala ultraderechista" (Payne, 1997, p. 555). En sus manos quedaban la prensa, la censura y la propaganda del Estado, con el apoyo de Juan Aparicio como director general de Prensa. Todavía los medios de comunicación dependían del falangismo oficial, pero su control recibía ya las críticas cada vez más abiertas de la jerarquía eclesiástica. El primado Plá y Deniel se quejaba de que el rigor de los censores falangistas ni siquiera respetaba la doctrina teológica de las revistas católicas (Lazo, 2008, p. 114).

La pugna general por ganar influencia ante el jefe del Estado tuvo un reflejo especial en el control de la prensa. El panorama cambió con la crisis gubernamental del verano de 1945. Franco volvió a confeccionar un gabinete de aparentes equilibrios, pero en el

\footnotetext{
${ }^{1}$ Decreto de creación de la Delegación Nacional de Prensa y Propaganda de FET y de las JONS, en $B O E$ del 17 de enero de 1937. Su marco teórico y desarrollo en Núñez de Prado, Sara (1995): "Hipótesis interpretativa del modelo de información franquista: 1936-39 y su proyección exterior", Revista de Historia Contemporánea, 6, pp. 289-304.

2 Para el estudio de la acción propagandística en el exterior y los conflictos entre diplomáticos y falangistas, véanse: González Calleja, Eduardo (1994): “El Servicio Exterior de la Falange y la política del primer franquismo" en Hispania. Revista Española de Historia, 186, pp. 279-307; Moreno Cantano, Antonio César (2006): "Unidad de destino en lo universal. Falange y la propaganda exterior (19361945)", en Studia histórica. Historia contemporánea, 24, pp. 107-131; Delgado Gómez-Escalonilla, Lorenzo (1992): Imperio de papel, Madrid, CSIC, y Pardo Sanz, Rosa: (1995): iCon Franco hacia el imperio! La política exterior española en América Latina, 1939-1945, Madrid, UNED.
} 
que los católicos asumían ya un papel predominante al tiempo que avanzaba el proceso de "desfalangización". Salió Arrese y la Secretaría General del Movimiento quedó vacante. En los medios de comunicación pronto se percibieron los cambios, inspirados en la doctrina expuesta por Carrero en sus informes a Franco (Tusell, 1993, pp.122-125).

En 1946 la prensa pasó a depender del ministerio de Educación Nacional, cuyo titular era el integrista católico Ibáñez Martín. Dos antiguos redactores de El Debate, Luis Ortiz Muñoz y Tomás Cerro Corrochano, sustituyeron a Arias Salgado y Aparicio (Tusell, 1984, pp. 188-210). En consecuencia, la censura se mantuvo y se extendió a la educación y la cultura. Sólo cambió de manos, pasando de los falangistas a los católicos. Fue un exponente más del triunfo del catolicismo franquista en detrimento de la Falange del Movimiento.

En cuanto a la política exterior, la llegada de Martín Artajo al ministerio también supuso la incorporación de las asociaciones católicas, que actuaron como un balón de oxígeno para la defensa del régimen en el exterior. Por ejemplo, Asuntos Exteriores protegió y subvencionó la participación española en los congresos de Pax Romana, la organización católica, fundada en 1921, que pretendía influir en la vida pública formando élites que defendieran las tesis del Vaticano (Sánchez Recio, 2005, pp. 213256). Cuando sus miembros salían de España, encabezados por Joaquín Ruiz Giménez, presentaban al régimen en los círculos internacionales con su cara más "amable" o menos dictatorial.

En esos años, la catolicidad oficial española y el anticomunismo radical fueron el eje de la política internacional del Gobierno. Con estos argumentos, el régimen de Franco intentaría abrirse alguna puerta en un mundo que, siguiendo las resoluciones de la ONU, le era mayoritariamente hostil. Las resoluciones de la primera Asamblea General no dejaban dudas al respecto ${ }^{3}$.

Los intentos por frenar la oleada de críticas internacionales se organizaron en dos frentes. En el primero, la acción diplomática española giró en torno a la Embajada en Washington, cuyo titular, Juan Francisco de Cárdenas, se reveló como un personaje clave para conseguir el apoyo de los círculos católicos y empresariales norteamericanos en beneficio del régimen ${ }^{4}$. En este sentido, el diplomático franquista

\footnotetext{
${ }^{3}$ En la primera (Res. 32/I), aprobada en Londres el 9 de febrero de 1946, se acordaba la no admisión de España en la ONU y se condenaba expresamente al régimen por no representar al pueblo español. (Once países todavía reconocían en ese momento al gobierno republicano de Giral). En la segunda (Res. 39/I), aprobada en Nueva York el 12 de diciembre, se calificaba como "fascista" al gobierno de Madrid por "su origen, naturaleza, estructura y comportamiento general" y se pedía (que) "los Estados miembros de las Naciones Unidas retiren inmediatamente todos sus Embajadores y Ministros plenipotenciarios que tiene acreditados en Madrid".

${ }^{4}$ Fue embajador en Washington en dos etapas. La primera con la República, entre 1932 y 1934, y la segunda como representante del gobierno de Franco, desde abril de 1939 hasta marzo de 1947.
} 
ya se había mostrado muy activo en Estados Unidos desde los años de la guerra civil. Cárdenas hubo de resistir la hostilidad, nunca disimulada, del Secretario de Estado Cordel Hull contra el gobierno de Franco (López Zapico, 2012, pp. 323-324). El segundo frente se articuló desde el interior del mismo ministerio de Asuntos Exteriores, para lo que Artajo atribuyó funciones de alto nivel a la Oficina de Información Diplomática ${ }^{5}$. Puso a su frente al abogado y periodista Luis María de Lojendio, al que le unía la misma adscripción ideológica y religiosa.

\section{El frente exterior: la embajada de España en Washington}

En 1945, el nuevo sistema internacional se diseñaba sin la participación española. Para el embajador de España en Washington la posición de la ONU había sido inspirada por "los enemigos de España", como calificaba al secretario general del organismo, Trigve Lie, y al presidente de la Asamblea, Paul Henri Spaak ${ }^{6}$.

La labor de Cárdenas ante los políticos y los medios de comunicación estadounidenses resultó especialmente ardua. Así lo reconocía en carta a su ministro José Félix de Lequerica, el 18 de enero de 1945: "Continuo siempre mi labor cerca de senadores, diputados y periodistas, machacando la verdad, esperando que algún día unos y otros nos crean y otros se hagan cargo de la realidad" ${ }^{7}$. En esta tarea le apoyaba desde Nueva York el diplomático Miguel Echegaray, nombrado en 1937 subdelegado de Prensa y Propaganda de la representación española.

Al mismo tiempo, los funcionarios de la embajada seguían de cerca los pasos del "grupo de Giral" y, en particular, los del antiguo embajador republicano Fernando de los Ríos, orientados a promover el aislamiento del gobierno franquista (reconocido por la Administración Roosevelt el 1 de abril de 1939). Informaban a Madrid de las gestiones realizadas por Negrín, Álvarez del Vayo o Isabel Oyarzábal en Nueva York y San Francisco, llegando a asegurar que los dirigentes republicanos "han vertido máximo ensañamiento y mala $\mathrm{fe}^{\prime \prime}{ }^{8}$.

La embajada volvió a editar el boletín Spain (suspendido en 1942), una publicación de 24 páginas, dirigida a fomentar la opinión favorable al gobierno de

\footnotetext{
${ }^{5}$ Con el mismo nombre ya existía un pequeño departamento al servicio, principalmente, del director general de Política Exterior.

${ }^{6}$ Telegramas no 1109 del 11 de noviembre 1946 y no 1158 del 10 de diciembre 1946, en Archivo General de la Administración (en adelante, AGA), Exteriores, 54/8769.

${ }^{7}$ En Archivo del Ministerio de Asuntos Exteriores y Cooperación (en adelante, AMAEC), leg. 2421, exp. 3.

${ }^{8}$ Telegrama no 1105 de 9 de noviembre 1946, en AGA, Exteriores, 54/8769.
} 
Franco en los ambientes culturales católicos y conservadores ${ }^{9}$. Las tareas de prensa eran responsabilidad de uno de los periodistas españoles más destacados de la historia del franquismo, Manuel Aznar, amigo personal de Franco, que llegó a Estados Unidos a finales de 1945 y permaneció en el puesto hasta enero de $1948^{10}$. Antes de trasladarse a Washington, se había distinguido por publicar en Arriba artículos en defensa de la neutralidad española, que fueron muy bien acogidos por la embajada de Estados Unidos en Madrid ${ }^{11}$. A pesar de estos precedentes, una vez en la capital estadounidense Aznar comprobó que las relaciones de la embajada española con la Secretaría de Estado eran casi inexistentes. Los militares norteamericanos destacaban el valor estratégico de España, en vísperas de que se proclamase la Guerra Fría, pero ningún diplomático quería recibir a un representante del Gobierno de Franco ${ }^{12}$.

El panorama empezó a cambiar con el trabajo de José Félix de Lequerica, el anterior ministro de Exteriores, antiguo embajador ante el régimen colaboracionista de Vichy ${ }^{13}$. A pesar de las resistencias iniciales de la Administración norteamericana, Lequerica se fue abriendo paso en los ambientes que más comprensión podían mostrar hacia el gobierno franquista (Cava, 1989, p, 227 y 279, entre otras). Con reconocida habilidad $y$ el empleo de grandes cantidades de dinero -que constantemente demandaba para desesperación de su ministro (Suárez, 2001, p. 451), Lequerica armó el llamado lobby español, un caso-modelo en la ejecución de una política de relaciones públicas aplicado a la diplomacia. Su objetivo era el levantamiento de las sanciones internacionales y la aceptación de España en las Naciones Unidas, lo que se consiguió en los años siguientes. Para ello, siguiendo la práctica habitual en Estados Unidos, contrató los servicios de un despacho de abogados especializado en el asesoramiento de congresistas, dirigido por Charles

\footnotetext{
${ }^{9}$ El primer número de esta nueva etapa es del 20 de febrero de 1946. Reproduce, entre otros, artículos publicados en las revistas británicas The Spectator y The Tablet, y en su contraportada invita a sus lectores estadounidenses a hacer turismo en España, con el siguiente eslogan: "Visit Spain. Enjoy a delightful spring in the most beautiful cities of Europe", en Archivo del Ministerio de la Presidencia del Gobierno (en adelante, AMPG), Jefatura del Estado, leg. 1670/12.

${ }^{10}$ Manuel Aznar Zubigaray (Etxalar, 1894 - Madrid, 1975). Durante diez años ocupó relevantes puestos diplomáticos. Fue embajador de España en la República Dominicana, Argentina, Marruecos y representante en la ONU. Como periodista, dirigió, entre otros medios, El Sol y La Vanguardia y presidió la agencia EFE. Véase: Tanco Lerga, Jesús (2004): Manuel Aznar: periodista y diplomático, Barcelona, Planeta.

${ }^{11} \mathrm{Su}$ agregado de prensa, Emmet J. Hughes, enviaba, el 4 de agosto de 1944, un memorándum al departamento de Estado asegurando que "Manuel Aznar está cooperando con nuestra oficina al grado más alto posible. Su columna militar que aparece cada día en la portada de Arriba es la expresión sana y articulada de la opinión española más neutral que pueda leerse", (citado por Pizarroso, 2009, en nota p. 70).

12 “No podíamos aspirar a ser recibidos por un funcionario de rango superior, o relativamente elevado. Nuestro máximo contacto posible llegaba hasta un secretario de Embajada", recordaba Aznar en La Vanguardia, el 14 de enero de 1973.

13 José F. de Lequerica (Bilbao, 1891 - 1963). Ejerció como embajador de hecho en Washington desde el 31 de octubre de 1948. Su nombramiento se oficializó el 4 de enero de 1951 y permaneció en el puesto hasta 1954.
} 
Patrick Clark, a quien, con un generoso contrato, asignó a la consejería de Relaciones Culturales de la embajada, cuyo titular era Pablo Merry del Val.

A José Félix de Lequerica, personaje tan controvertido en la diplomacia del periodo, no se le debe sustraer el mérito de haber sido el primer embajador español en comprender, en un sentido moderno, el alcance de los medios informativos como agentes cooperadores de la acción diplomática.

\section{El frente interior: La Oficina de Información Diplomática}

La Oficina de Información Diplomática del ministerio de Asuntos Exteriores (OID) ${ }^{14}$ fue una pieza fundamental del esquema propagandístico de los primeros años del franquismo. Este "instrumento al servicio del Cuerpo diplomático" -como lo definió años después el ministro Martín Artajo- fue diseñado para articular la réplica a las campañas de desprestigio provenientes de las potencias vencedoras de la guerra mundial.

En ese contexto Martín Artajo acometió la transformación de su departamento, con la ley del 31 de diciembre de 1945 sobre la Organización de los Servicios del Ministerio de Asuntos Exteriores (BOE, 2 de enero de 1946). Antes de emprender la reforma de Exteriores, la Jefatura del Estado había esperado a la conclusión de la guerra, como se explica en el texto de presentación de la ley, donde se lee que:

Diferida la reorganización del Ministerio de Asuntos Exteriores hasta el final de la guerra, para evitar que las modificaciones hechas en el curso de ella le dieran carácter circunstancial, es llegado el momento de reajustar el órgano directivo de nuestra política exterior, a fin de acrecentar su eficacia.

No obstante, el Servicio exterior del Gobierno había sido ya sometido a dos reformas internas. La primera, con motivo de su constitución como tal departamento ministerial (ley de 30 de enero de 1938, publicada en el $B O E$ del 31); y la segunda, que desarrollaba la anterior, a través de una Orden del 29 de enero de 1942 (en BOE, del 3 de febrero). En la ley de 1938 la estructura interna del nuevo ministerio se limitaba a las direcciones de: Política Exterior, Tratados Internacionales, Relaciones con la Santa

\footnotetext{
14 Recuperó su denominación tradicional en diciembre de 2011 (Real Decreto 1887/2011 de 30 de diciembre), que, en su art. 1, ap. E, creaba la dirección general de Medios y Diplomacia Pública y restablecía la Oficina de Información Diplomática, con su función clásica como portavoz del Ministerio de Asuntos Exteriores. Entre 2004 y 2011 la Oficina había cambiado su nombre, no sus contenidos básicos, por el de dirección general de Comunicación Exterior (Real Decreto 1416/2004 de 11 de junio).
} 
Sede y Protocolo. En la Orden posterior, se ampliaban ya las funciones de la subsecretaría y de la dirección general de Política Exterior, al tiempo que se creaban otras nuevas direcciones, como Política Económica y Asuntos Generales, y las secciones de Protocolo y del Gabinete Diplomático.

La diplomacia del régimen se preparaba entonces para dar su gran batalla internacional contra el aislamiento -el "cerco", en la terminología resistente empleada por los medios más afines-. Los miembros de la Carrera respondían con una sola voz, pero no por eso habían desaparecido las tendencias aliadófilas o germanófilas de sus componentes. La postura mayoritaria pasó por una etapa pro alemán, siendo Serrano Suñer su titular, entre octubre de 1940 y septiembre de 1942 (Marquina Barrio, 1989, pp. 145-168). Serrano contó con la colaboración del diplomático falangista Felipe Ximénez de Sandoval, a quien nombró jefe de su gabinete y reforzó en la Delegación Nacional del Servicio Exterior de FET y de las JONS (Payne, 1997, pp. 513-515).

Tras la salida de Serrano, Franco había llamado al general Gómez Jordana para ocupar, por segunda vez, el ministerio de Exteriores, donde se rodeó de diplomáticos que, como él, defendían posiciones próximas al neutralismo, conocedores de la marcha de la guerra mundial hacia el triunfo de los aliados (Tusell, 1995, pp. 348, 646 y 664, entre otras).

Pero a finales de 1945, una vez concluida la contienda, en el terreno de la propaganda exterior no había espacio, al menos oficialmente, para discrepancias ideológicas internas. La diplomacia española se orientaba al objetivo común de hacer frente a las "campañas difamatorias" y "vindicar la razón de España frente a la sinrazón de medio mundo", en palabras de Artajo $^{15}$. Para ello contaba con unos diplomáticos que formalmente cerraban filas en torno a las órdenes que emanaban del Palacio del Pardo. El propio Franco se referirá a ellos, poco después, como "la vanguardia de España en esta nueva guerra" ${ }^{16}$.

La identificación de los diplomáticos con el franquismo fue absolutamente mayoritaria desde los primeros días de la guerra civil. "De los casi 390 diplomáticos de antes del 18 de julio de 1936, sólo 55 permanecieron leales a la legalidad constitucional" (Viñas, 2010, p. 296). Unos, cesaron en sus funciones o conspiraron desde sus destinos en el exterior; y otros, abandonaron sus puestos en Madrid. En su gran mayoría eran católicos tradicionales y monárquicos y algunos ya habían ocupado cargos de alta responsabilidad en tiempos de Alfonso XIII. En general, les unía una marcada anglofilia, en la que sobresalía el duque de Alba, embajador oficioso en Londres desde 1937.

\footnotetext{
${ }^{15}$ Discurso ante el pleno de las Cortes, el 14 de diciembre de 1950.

${ }^{16}$ Alocución de Franco en el ministerio de Asuntos Exteriores, el 7 de octubre de 1947, en los actos conmemorativos del aniversario de la batalla de Lepanto.
} 
Las máximas autoridades del régimen se reservaban la relación directa con Berlín y Roma, mientras que este núcleo de diplomáticos conservadores entablaba contactos con los representantes de la alta sociedad europea, con quienes, en algunos casos, mantenía vínculos familiares. Un Decreto del 11 de enero de 1937 creó el nuevo Cuerpo diplomático de la España "nacional". Para pertenecer a él todos sus miembros hubieron de superar la evaluación de una Comisión depuradora (Decreto del 29 de enero de 1937) a fin de esclarecer su actuación en los días de la sublevación ${ }^{17}$.

Ya desde el comienzo de la guerra civil, las relaciones exteriores del franquismo habían sido ejecutadas bajo la supervisión directa de la Jefatura del Estado. Su Gabinete diplomático se creó en los primeros días de la sublevación militar (Decreto del 30 de julio de 1936) y estuvo dirigido por el embajador José Antonio Sangróniz ${ }^{18}$. El gabinete se ocupó de establecer la relación con los representantes de los Gobiernos que se iban aproximando a Burgos. El primero que formalizó la presentación de sus Cartas Credenciales fue el italiano Roberto Cantalupo en nombre del Duce; después, el general alemán Von Fauppel, enviado por Hitler. Ya antes, El Salvador y Guatemala habían reconocido al nuevo Estado español (8 de noviembre de 1936).

A principios de 1937, el gabinete de Sangróniz estaba integrado por otros cinco diplomáticos profesionales: Julio de Palencia Álvarez, Manuel de Travesedo Silvela, Germán Baráibar Usandizaga, Federico Oliván Bago y José María Garay y Garay. Destinados en el Cuartel General de Salamanca, sus funciones estaban relacionadas con el asesoramiento en cuestiones internacionales y de protocolo ${ }^{19}$. El grupo -de gran influencia ante Franco- era autónomo de la Secretaría de Relaciones Exteriores de la Junta Técnica del Estado (creada por Decreto del 1 de octubre de 1936), a cuyo frente figuraba el embajador Francisco de A. Serrat y Bonastre, en el que estaban destinados otros once miembros de la Carrera diplomática. En total, la diplomacia franquista de la primera hora, organizada en Salamanca, estaba formada por no más de 25 miembros sin contar a los que ya ocupaban puestos en el exterior.

A pesar de su adscripción a la causa de los sublevados, los diplomáticos de Franco se integraron en la Falange sólo minoritariamente. Mantuvieron su poder mientras Serrano Suñer conservó su gran influencia ante el jefe del Estado. Pero después fueron

\footnotetext{
17 La situación del cuerpo diplomático español durante la guerra civil y la depuración de sus miembros, en: Viñas, Ángel (Dir.) (2010): Al servicio de la República, Madrid, Marcial Pons; Casanova, Marina (1996): La diplomacia española durante la guerra civil, Madrid, Ministerio de Asuntos Exteriores, Colección Diplomática Española, y Pérez Ruiz, José L. (2005): Las depuraciones de la carrera diplomática española (1931-1980), Burgos, Dossoles.

18 José Antonio de Sangróniz y Castro, marqués de Desio (1895 - 1980). Al proclamarse la Segunda República era secretario en la embajada de Chile; pasó a situación e expediente forzoso en enero de 1933. Entregó a Franco su propio pasaporte diplomático para facilitar su entrada en el Marruecos francés en las horas previas al inicio de la sublevación militar del 18 de julio.

${ }^{19}$ La relación completa del servicio diplomático del Cuartel General de Franco en Salamanca en AMAEC, leg. 1031, exp. 90.
} 
cediendo sus puestos, primero ante militares de tendencia anglófila y, más tarde, ante representantes del catolicismo político.

La reforma de Artajo a finales de 1945 terminaba con esta sucesión de tendencias ideológicas en el seno del Servicio Exterior. Se acababan las luchas entre las "tres grandes burocracias" de las que se servirá Franco (Martorell y Juliá, 2012, p. 329) y se imponía de momento el ideario de la dirección eclesiástica, vinculada a la Asociación Católica Nacional de Propagandistas o la antigua CEDA. La reforma de ese año intentaría aunar "fidelidad a la tradición" incrementando "la cohesión deseable", según se decía en la presentación de la ley. Entre sus principales novedades figuraba la creación de la dirección general de Relaciones Culturales, sobre la que, recogiendo los intentos esbozados en la época de Primo de Rivera, habría de girar el concepto de Hispanidad como eje de la política exterior del momento.

La reorganización de Asuntos Exteriores alcanzó a casi todos los niveles del ministerio, sin olvidar la preparación de los futuros diplomáticos, pues la ley contempló un aumento en las plantillas de la Carrera diplomática, de hasta 25 por año. Se trataba de un aumento "ya requerido también por las necesidades crecientes de nuestras representaciones en el extranjero".

La ley se componía de 23 artículos, tres disposiciones adiciones, siete transitorias y una derogatoria. En su artículo primero establecía la composición de los Organismos y Servicios que dependían del Ministerio de Asuntos Exteriores, "al que compete la realización de la política exterior del país". Además, fijaba varios órganos asesores del ministro: el Instituto de Cultura Hispánica, la Junta del Patronato de la Obra Pía, el Consejo Superior de Misiones, la Junta de Relaciones Culturales, la Oficina de Información Diplomática, la Asesoría Jurídica Internacional y la Abogacía del Estado.

La OID se creará con la finalidad primordial de servir de asesoramiento al ministro de Asuntos Exteriores en materia informativa. A su cometido específico se dedica el artículo 19 de la ley, que, sin embargo, se redacta en términos genéricos, pues sólo se dice que "la Oficina de Información Diplomática tendrá a su cargo los servicios de información sobre las cuestiones que puedan interesar al Departamento, tanto a los organismos centrales como a sus representaciones diplomáticas".

Sobre la nueva OID recaerá el principal esfuerzo de información y, muy especialmente, de contra-propaganda, en defensa de la imagen exterior del régimen. Para disipar dudas, el ministro envió una Circular a "todos los jefes de Misión" en la que se advierte el carácter defensivo y replicante con que ha nacido la Oficina. Artajo les avanzó que la OID les serviría material informativo, “(...) con objeto pueda en todo momento difundir verdad España por medio boletines adecuados y rectificar o completar noticias tendenciosas o deficientes".

El ministro también les solicitó que, a través de la valija diplomática, enviasen: 
Primero: información, ambiente en general y sugestiones personales sobre campañas que V.E. juzgue oportuna; segundo: labor que hoy realice al respecto y medios difusión que cuenta; tercero: datos bien ordenados sobre periódicos y sus tendencias, personalidades, entidades, comunidades, afectos a España... A este respecto, interesa remita anuarios generales, guías, actividades particulares y trabajos estadísticos.

Y terminó empleando el tono habitual de sus escritos: "Encarezco máxima objetividad en esta labor y el mayor celo" ${ }^{20}$.

Años después, ya en 1950, cuando una nueva resolución de la ONU levantó el aislamiento sobre España ${ }^{21}$, un Martín Artajo satisfecho explicaba en las Cortes, por primera vez, las condiciones del bloqueo y la forma en que se le había hecho frente desde su departamento. Su intervención fue un homenaje a los diplomáticos españoles que "en defensa de nuestras instituciones patrias, habían luchado con orgullo y pasión delante de cada una de nuestras Cancillerías". No se olvidaba de la Oficina de Información Diplomática, que fue

(...) un verdadero arsenal de informaciones, noticias, documentos y textos para promover a nuestros representantes en el exterior de toda la munición dialéctica enderezada a pulverizar la falaz propaganda de nuestros adversarios y a contrarrestar con la información real y verdadera de nuestras cosas, que tantas veces sus grandes agencias informativas callan, deforman o silencian ${ }^{22}$.

\section{Lojendio, propagandista de la política exterior y activista}

Como se ha adelantado, el primer responsable de la OID fue Luis María de Lojendio Irure, que accedió al puesto con el nombramiento de Jefe técnico, según acuerdo del Consejo de Ministros del 18 de enero de 1946. Permaneció en ese destino hasta el 23 de enero de 1958. Por tanto, desempeñó esa responsabilidad durante doce años, los mismos que Martín Artajo al frente del departamento ${ }^{23}$.

\footnotetext{
${ }^{20}$ Circular no 67 de 14 de marzo de 1946, en AMAEC, leg. 1769, exp. 5.

${ }^{21}$ La Resolución 386/V, aprobada por la Asamblea General el 4 de noviembre de 1950, revocaba la Resolución 39/I, al recoger la doctrina por la que el establecimiento de relaciones diplomáticas con un país no implica juicio alguno respecto a su régimen interno. A partir de ese momento, España iniciaba su proceso de ingreso en los organismos técnicos especializados vinculados a la ONU.

22 Discurso ante el plenario de las Cortes, antes citado, del 14 de diciembre de 1950.

${ }^{23}$ La Oficina de Información Diplomática sería elevada a la categoría administrativa de dirección general por el Decreto 60/1960 de 14 de enero, debido a "la crecente importancia de los asuntos
} 
Lojendio proviene del sector católico y su elección para el nuevo cargo garantiza la continuidad en la función, ya que, durante buena parte de la guerra, estuvo destinado en el Gabinete diplomático del Jefe del Estado, encargado de tareas relacionadas con la información y la propaganda. Es hijo de un abogado del Estado y pertenece a una familia estrechamente vinculada a los círculos católicos y, en particular, a la Compañía de Jesús. Su personalidad ofrece múltiples facetas. Fue abogado, corresponsal de guerra, propagandista del régimen y alto cargo del ministerio de Asuntos Exteriores... y también pintor, historiador de la cultura vasca, conferenciante de arte, monje benedictino y hasta prior del monasterio del Valle de los Caídos ${ }^{24}$.

Ya antes de la guerra civil era un personaje conocido en los ambientes culturales y artísticos de San Sebastián, en los que fue introducido por su hermano José María, presidente de la Academia de la Lengua Vasca. Luis María realizó sus primeras exposiciones de pintura en los años treinta e impartió conferencias sobre los principales movimientos artísticos de la época, tal como recoge la prensa guipuzcoana de aquellos años ${ }^{25}$. Además, investigó en las raíces históricas y sociales del pueblo vasco, publicando sus aportaciones, en 1935, en la prestigiosa Revista de Estudios Internacionales Vascos ${ }^{26}$.

Sus vinculaciones religiosas le llevaron a trabajar como abogado de los sindicatos católicos de Guipúzcoa, tarea que compartió con una intensa vida social como miembro de la sociedad cultural y gastronómica GU ("Nosotros"), en la que se relacionó con el pintor Jesús Olasagasti, el arquitecto José María Aizpurúa, el compositor Juan Tellería y los escritores falangistas Eugenio Montes, Rafael Sánchez Mazas y Ernesto Giménez Caballero. La sociedad era famosa entonces por sus certámenes musicales, exposiciones, bailes, etc. También eran muy comentados sus acalorados debates, en los que solía tomar parte Pío Baroja. Ese círculo cultural fue un auténtico centro de reclutamiento de la Falange, especialmente a partir de la llegada de José Antonio Primo de Rivera, invitado a pronunciar una conferencia en el verano de 1934. En esas mismas fechas también pasó por GU Pablo Picasso junto a su esposa

encomendados a dicha Oficina", siendo ministro de Asuntos Exteriores Fernando María Castiella. Ya dos años antes, por la Orden de 25 de enero de 1958, se había establecido que su titular sería miembro de la Carrera diplomática. Así ha sido desde entonces con la única excepción del periodo comprendido entre octubre de 2010 y enero de 2012.

${ }^{24}$ Luis María de Lojendio Irure (San Sebastián, 1907 - Leyre, 1987). Al dejar su cargo en la OID en 1957, fue destinado a Buenos Aires como cónsul general, puesto en el que permaneció sólo unos meses, para ingresar en 1960 en la Orden benedictina, de la que fue nombrado Abad en diciembre de 1968. Como prior del Valle de los Caídos, recibió el cadáver de Franco para su inhumación en esa basílica el 22 de noviembre de 1975. Murió a los 80 años en el monasterio de Leyre (Navarra).

25 Disponible en: http://www.euskomedia.org/PDFAnlt/arte/23/23561573.pdf (Consultado en julio, 2012). Véase también: Lojendio Osborne, Juan B.: "Relación entre la obra gráfica y pictórica en Luis María de Lojendio", tesis doctoral no publicada, leída en la Facultad de Bellas Artes de la Universidad de Sevilla en 2008.

26 Disponible en: http://www.euskomedia.org/PDFAnlt/riev/26/26005043.pdf (Consultado en julio, 2012). 
Olga Koklova y, según Giménez Caballero, llegó a mantener una breve conversación con el fundador de la Falange ${ }^{27}$.

Al principio de la guerra, y tras una breve estancia en prisión, Lojendio se integró en el ejército del general Mola. Poco después e instaló en Salamanca y formó parte como Agregado de prensa del Gabinete diplomático del Cuartel General. A partir de ese momento, siguió a Franco en todos sus desplazamientos, lo que le permitió presenciar directamente los principales episodios bélicos. Sirviéndose de sus propias anotaciones escribió Operaciones militares en la Guerra de España, en cuyo prólogo, fechado en San Sebastián, el 20 de septiembre de 1939, dice: "He seguido la marcha de todas las operaciones en todos los frentes de combate, cuyo trazado he recorrido. He asistido a las principales batallas de la contienda..." ${ }^{28}$. Su trabajo consistía en la elaboración de dos notas diarias, una a medio día y otra a las siete de la tarde, con el resumen de los principales hechos militares. Estas notas, supervisadas por su jefe inmediato, el teniente coronel Antonio Barroso, jefe de la Sección de Operaciones del Estado Mayor, eran destinadas a los corresponsales de la prensa nacional y extranjera que informaba desde los frentes de combate. Su contenido se nutría también de las aportaciones que le suministraban el jefe de los Servicios de Prensa extranjera, Jesús Pabón, y el jefe de los corresponsales en los frentes, Manuel de Lámbarri. Las notas servían asimismo "como orientación general de censura" ${ }^{29}$ y eran distribuidas por los Oficiales de prensa.

El Cuerpo de Oficiales de prensa se creó en el verano de 1937 (BOE del 28 de julio de ese año), por iniciativa de Luis Antonio Bolín ${ }^{30}$, siguiendo el modelo alemán. Se encargaba de la "vigilancia periodística y de atender a las personalidades extranjeras que deseen visitar la España liberada", según se marcaba en el decreto de su creación, que, además, establecía la obligatoriedad de presentarse uniformados, obedecer al mando militar o civil, según los casos, saber idiomas y poseer titulación universitaria o cualificación profesional idónea (Moreno, 2008, pp. 39-41).

Lojendio no ejerció la profesión periodística directamente aunque, en los primeros meses de la guerra civil, desempeñó tareas informativas en el frente para el Diario Vasco de San Sebastián, hasta enero de 1937. Según él mismo hizo constar en su

\footnotetext{
${ }^{27}$ Véase López de Sosoaga, María Jesús (2004): “Jesús Olasagasti, animador del protagonismo cultural que tuvo San Sebastián antes de la guerra civil", en Ondare, 23, pp. 561-573.

${ }^{28}$ Lojendio, Luis María de (1939): Operaciones militares en la guerra de España, 1936-1939, Barcelona, Montaner y Simón, p. 14.

${ }^{29}$ Lojendio: Operaciones..., p. 15.

${ }^{30}$ Málaga, 1894 - 1969. Corresponsal de $A B C$ en Londres, se le encomendó la contratación del Dragón Rapide, el avión que recogió a Franco en Las Palmas el 17 de julio de 1936 y le permitió iniciar, horas después, la sublevación militar. Cuenta su participación en el complot en su libro de memorias (1967): España, los años vitales, Madrid, Espasa-Calpe, pp. 25-68, que incluye detalles posteriormente desmentidos por Ángel Viñas en (2011): La conspiración del general Franco, Barcelona, Crítica, pp. 1127. Fue responsable de la prensa nacional y extranjera desde casi el comienzo de la guerra civil hasta finales de 1937.
} 
solicitud de inscripción en el Registro Oficial de Periodistas, había sido, además, redactor del semanario Noticiario de España, desde su fundación en septiembre de 1937. Era una publicación de la sección de Prensa Extranjera del ministerio de la Gobernación, que se distribuía también en inglés y francés. Su trabajo consistía en redactar "una crónica general de las operaciones militares", que se publicaba sin firma en órganos de la propaganda dirigidos a las principales Embajadas, como Occident (París), Spain (Londres y Nueva York) u Orientación Española (Buenos Aires). Tras estas credenciales, fue inscrito en el citado Registro profesional en 1940, con el número $1.122^{31}$.

A su llegada al ministerio de Asuntos Exteriores su acción se va a concentrar en los periódicos. Siguiendo las instrucciones de Martín Artajo, controlará el tratamiento informativo de los temas diplomáticos, con la ayuda del diplomático Juan de las Bárcenas, a quien había conocido durante la guerra en el Gabinete diplomático del Cuartel General de Franco. Lojendio retomará así su antiguo interés por la política exterior y se convertirá en uno de sus más prominentes propagandistas. Durante más de una década, su actuación profesional cumplirá los requisitos teóricos de la propaganda, sabiendo relacionar persuasión e información (Pizarroso, 1990, pp. 2541), y contribuyendo a que Exteriores ocupe un lugar predominante en la creación de la nueva imagen del Estado franquista: católico, anticomunista, dispuesto a alinearse militarmente con Estados Unidos y receptivo a la inversión económica extranjera.

La información diplomática tenía una presencia muy frecuente en la prensa española en esos años. Sólo debía cumplir un requisito, que, cierta o no, fuera favorable a los intereses gubernamentales. Sin embargo, en el ministerio se tenía constancia clara de que las opiniones favorables a los intereses españoles resultaban minoritarias en relación a las numerosas protestas y críticas que publicaban los periódicos más influyentes del mundo. Casi a diario, llegaban a la sede de Santa Cruz resúmenes de prensa internacional con artículos muy negativos para el régimen. Cómo un ejemplo, entre tantos posibles, figura el telegrama remitido por el embajador Bulnes desde Buenos Aires, en el que el diplomático no se privaba de dar su particular opinión sobre las noticias referentes a España aparecidas en la capital argentina:

Asuntos España vuelven ocupar columnas enteras toda esta prensa llenas de falsas noticias, tendenciosamente confusas, demostrando obedece sistemática campaña difamación, con entero desconocimiento realidad española ${ }^{32}$.

De los registros de entrada oficiales correspondientes a 1946 se desprenden dos conclusiones respecto a la recién creada OID: primera, que el flujo de información con destino directo a la nueva oficina era muy pequeño en relación a las direcciones de mayor contenido político, y, segunda, que las notas que le trasladaban por esta vía

\footnotetext{
${ }^{31}$ Su expediente en el Registro Oficial de Periodistas en AGA, Presidencia, 52/13928.

${ }^{32}$ Telegrama del 8 de enero de 1946, en AMPG, Jefatura del Estado, leg. 1673/1.
} 
desde embajadas y consulados no eran, en la mayoría de los casos, más que recortes de prensa con artículos o comentarios negativos para Franco y su Gobierno o que informaban de las actividades de personalidades políticas exiliadas en los países de procedencia $^{33}$.

Hasta la creación de la OID, las tareas de acopio, evaluación y, en su caso, respuesta a la ingente cantidad de informaciones que recogían y enviaban a Madrid las representaciones españolas se canalizaban a través del Gabinete del titular de Exteriores o de la dirección de Política Exterior, dirigida por José María Doussinague, que, ejerciendo una gran influencia, trabajó en la planificación de las relaciones internacionales del primer franquismo ${ }^{34}$. Fue, desde 1943, el ideólogo principal de la posición neutralista defendida por Gómez Jordana. Redactó un Ilamado "Plan D" que pretendía situar a España al frente de los países neutrales europeos, con el apoyo del Vaticano, para buscar una paz negociada que, tras la previsible victoria aliada, le permitiera mejorar su posición internacional (Tusell, 1995, pp. 338-349). No fue más que un proyecto que exageraba las posibilidades reales de la diplomacia española en ese momento. Las funciones de Doussinague alcanzaban también a la relación con los medios informativos extranjeros acreditados en Madrid. Era su interlocutor oficial y quien se relacionaba con las embajadas y sus respectivos consejeros de Prensa (Pizarroso, 2009, p. 61).

Ya el ministro Lequerica se esforzó por unificar las instrucciones que se enviaban a las legaciones en el exterior. Estas recibían desde Madrid un caudal de órdenes, no siempre en la misma dirección, pues, en ocasiones, el ministerio era ajeno a las directrices que remitía la Delegación Nacional de Prensa y Propaganda o, incluso, la Falange Exterior, lo que originaba malentendidos y enfrentamientos frecuentes. Pero la marcha de los acontecimientos internacionales obligaba a unificar los criterios de la política exterior en un momento en que la Comisión de Asuntos Generales de la Conferencia de San Francisco empezaba a debatir la propuesta de exclusión de España por su pasada relación con los países del Eje. El 26 de junio de 1945, Lequerica envió una Circular a los jefes de Misión dando instrucciones para enfrentarse dialécticamente a la campaña internacional contra al gobierno español. No son más que "tergiversaciones de nuestros enemigos" -señalaba-, que forman un "embarullamiento vociferante", si bien "España no va a dejarse impresionar por vaga palabrería intrínseca y electorera de algunos delegados".

Desde entonces, cualquier iniciativa externa tendría respuesta por parte española. El cambio de ministro no modificó esta disposición; al contrario, la reforzó. En cuanto

\footnotetext{
33 "Libro de Registros de Entrada, Ministerio de AA. EE., 1946", en AGA, Exteriores, 54/6095.

34 José María Doussinague y Teixidor (Montevideo, 1894 - Obaños, Navarra, 1967). Seguramente, el miembro de la carrera diplomática española más destacado de los años cuarenta. Su ideario neutralista en España tenía razón (1939-1945) (1949): Madrid, Espasa-Calpe.
} 
accedió a su despacho en el palacio de Santa Cruz, Artajo envió, el 11 de agosto de 1945, un documento de once páginas a todas las embajadas y misiones contra "la intensa campaña de difamación que viene siendo objeto España, (que) requiere máximo esfuerzo para poner en su punto verdades tan oscurecidas y tergiversadas, no solo en medios oficiales sino en todos los que puedan considerarse importantes". En su Circular desarrollaba los cinco puntos que habrían de servir de argumentación para elaborar una respuesta, basada en la situación que vivía España en 1936, la justificación del posterior alzamiento militar y la recuperación económica y cultural que, en su opinión, ya se observaba en la sociedad española:

- Los españoles vivían entonces "bajo la tiranía más despótica” (...).

- "Miles y miles de asesinatos" se cometían "en la zona roja" (...).

- Ante esta situación era lógica la respuesta "entusiasta de una masa nacional, capaz de sacudirse el yugo intolerable con el que le oprimía la tiranía demagógica" (...).

- Los españoles de la "zona nacional" ofrecían su "acatamiento de la pura doctrina cristiana y a la autoridad de la Cátedra de San Pedro"(...).

- Así las cosas, se producía el "restablecimiento de nuestra economía, debido a la paz social y el intensísimo movimiento cultural" (...).

En definitiva -terminaba-, España es “una nación en la plenitud de su vigor" ${ }^{35}$.

Al comenzar 1946, el ministro recibía a la prensa española para describir un panorama halagüeño que, como se demostraría muy pronto, poco tenía que ver con la realidad. Artajo decía:

Hay motivos fundados para un sosegado optimismo. Hemos pasado los seis primeros meses de postguerra que tenían por fuerza que ser los más difíciles (...) y soportando una campaña de prensa casi sin precedentes (...). No tenemos pleito ninguno de carácter internacional y nuestras relaciones exteriores son buenas con casi todos los países. Es más: el gobierno ha zanjado generosamente algunas diferencias mínimas que pudiéramos tener con alguna nación (...). Nuestras dificultades obedecen al designio de algunos sectores de opinión de determinados países de hacer política interna a costa nuestra (...). La ofensiva verbalista tiene por fuerza que deshacerse porque se enfrenta a un gobierno con conciencia de su poder y responsabilidad (...). Los augurios de 1946 son, pues,

${ }^{35}$ El texto de las Circulares de Lequerica y de Martín Artajo en AMPG, Jefatura del Estado, leg, 1668/5. 
francamente buenos por lo que se refiere a las relaciones exteriores de nuestra patria $^{36}$.

Para conocer la opinión escrita de Luis María de Lojendio sobre tan crítico periodo, hemos de remitirnos a una publicación posterior, cuando el panorama había cambiado beneficiosamente para el régimen y el propio Lojendio había optado por su apartamiento de la vida pública. En 1953, ya recluido en el monasterio de Leyre, recordaba que, al terminar la guerra mundial, "se va cargando el ambiente internacional" contra España en los organismos internacionales, porque -dice- la ONU tiene, entre sus objetivos iniciales, el aislamiento del régimen español"37. Habían muerto Roosevelt y Churchill y

(...) los sucesores de uno y otro rompían con la línea política que aquéllos mantuvieron con España en los últimos días del conflicto mundial. Truman era muy sensible a las campañas de prensa y en su inexperiencia estaba entregado a los funcionarios más sectarios del Departamento de Estado. En cuanto al mayor Atlee, era ya beligerante desde la guerra española. Su figura saludando a la manera comunista con el puño cerrado, fue publicada por la prensa cuando visitó a las Brigadas Internacionales en los días del Jarama ${ }^{38}$.

En su opinión, la resolución de la ONU había causado "un movimiento inverso" al que se pretendía, pues (...) "Franco, que cuenta siempre con la ejemplar amistad portuguesa, iniciará un hábil juego político apoyándose en (...) vínculos profundos de historia y raza: los pueblos hispanoamericanos y los países árabes" ${ }^{39}$.

Esta era la visión de Lojendio desde su retiro monacal pasados ya los tensos años del bloqueo internacional. Ahora, se dedicaba a la investigación histórica y a la crítica artística. Ya había abandonado su antigua preocupación por las cuestiones internacionales. Desde la tranquilidad de Leyre, volcaba su interés en personajes históricos, como Gonzalo de Córdoba o Savonarola; también sobre las rutas románicas navarras y del norte de Castilla, sin olvidarse de redactar una guía del monasterio benedictino en el que residía y se había formado religiosamente.

\footnotetext{
${ }^{36}$ Las declaraciones a la prensa se realizaron la tarde del 8 de enero de 1946 y, en un amplio resumen, fueron remitidas a las Representaciones españolas en el exterior en la Circular del 9 de enero, en AMPG, Jefatura del Estado, leg. 1672/1. Ese mismo día se recogieron en los principales medios, entre otros en $A B C, 9$ de enero 1946, p. 9.

37 Lojendio Luis María de (1976): “Guerra y neutralidad en España (1936-1946)”, en Jover Zamora, José M.: Historia Universal, tomo XI, Madrid, Espasa Calpe, pp. 155-269.

38 Ibídem, p. 265.

39 Ibídem, p. 268.
} 


\section{Conclusiones}

En el presente trabajo hemos intentado demostrar, siguiendo las aportaciones de los últimos años, que la respuesta de la diplomacia española a su aislamiento, dictado por las resoluciones de la ONU entre 1946 y 1950, se articuló desde el ministerio de Asuntos Exteriores. Su titular, Alberto Martín Artajo, sin desviarse de las directrices de Franco y Carrero, se mostró eficaz en relación a los fines que perseguía: la permanencia del régimen y su paulatina aceptación en la comunidad internacional. Entretanto, encabezó el sector católico en la lucha interna con otras facciones del franquismo -militares y falangistas principalmente-, a las que fue desplazando de la primera fila del poder hasta marcar la preponderancia del activismo católico en todos los órdenes de la vida pública española de esos años.

A partir de 1945, el sistema internacional diseñado por las potencias vencedoras de la guerra mundial, contrario al gobierno español por su carácter totalitario y su pasada relación con Alemania e Italia, obligó al departamento de Exteriores a asumir una posición de réplica permanente. Artajo, dentro de una profunda reforma, dotó al ministerio de un instrumento que pudiera coordinar sus esfuerzos en materia de comunicación, la Oficina de Información Diplomática, un órgano apenas mencionado en la bibliografía. Su estudio nos ha permitido confirmar la existencia de una estrecha relación entre la política exterior y la información, especialmente evidente en esos años. Su primer director fue Luis María de Lojendio, un personaje rico en matices, que pasó de la primera línea de los frentes de guerra al retiro de los monasterios benedictinos, sin dejar nunca de ser un distinguido propagandista de la política exterior del régimen de Franco.

\section{Bibliografía citada}

BARRERA, CARLOS (1995): Periodismo y franquismo. De la censura a la apertura, Barcelona, Ediciones Internacionales Universitarias.

CAVA MESA, MARÍA JESÚS (1989): Los diplomáticos de Franco: J. F. Lequerica, temple y tenacidad (1890-1963), Bilbao, Universidad de Deusto.

CAZORLA SÁNCHEZ, ANTONIO (2000): Las políticas de la victoria. La configuración del Nuevo Estado franquista (1938-1953), Madrid, Marcial Pons.

DOMÍNGUEZ ARRIBAS, JAVIER (2010): «L'organisation de la presse et de la propagande dans l'Espagne rebelle (1936-1939)», El Argonauta Español, 7. Disponible en: http://argonauta.imageson.org/document139.html 
EIROA SAN FRANCISCO, MATILDE (2009): Política internacional y comunicación en España (1939-1975). Las cumbres de Franco con jefes de Estado, Madrid, Ministerio de Asuntos Exteriores y Cooperación, Biblioteca Diplomática.

GONZÁLEZ CALLEJA, EDUARDO (2011): “La propaganda exterior de FET y de las JONS (1936-1945), en Moreno Cantano, Antonio C. (Coord.): El ocaso de al verdad. Propaganda y prensa exterior en la España franquista (1939.1945), Gijón, Trea, pp. 157-190.

LAZO DÍAZ, ALFONSO (1997): La Iglesia, la Falange y el fascismo. Un estudio sobre la prensa española de posguerra, Sevilla, Universidad de Sevilla. 1998.

LAZO, DÍAZ, ALFONSO (2008): Una familia mal avenida. Falange, Iglesia y Ejército, Madrid, Síntesis.

LÓPEZ ZAPICO, MISAEL A. (2012): "El diplomático Juan Francisco de Cárdenas durante la guerra civil española y el primer franquismo", en Moreno Cantano, Antonio César (Coord.): Propagandistas y diplomáticos al servicio de Franco (1936-1945), Gijón, Trea., pp. 303-331.

LLEONART, JOSÉ A. (1978-2002): España y ONU (1945-1955), 6 vol., Madrid, CSIC.

MARQUINA BARRIO, ANTONIO (1989): "La etapa de Serrano Suñer en el Ministerio de Asuntos Exteriores", en Espacio, Tiempo y Forma, serie V, 2, pp. 145-168.

MARTÍNEZ LILLO, PEDRO (2000): "La política exterior de España en el marco de la Guerra Fría", en Tusell, Javier: La política exterior de España en el siglo XX, Madrid, Biblioteca Nueva, pp. 323-340.

MARTORELL, MIGUEL Y JULIÁ, SANTOS (2012): Manual de historia política y social de España (1808-2012), Barcelona, RBA.

MORENO CANTANO, ANTONIO CÉSAR (2008): "Los servicios de prensa extranjera en el primera franquismo (1936-1945)", tesis doctoral defendida en la Universidad de Alcalá de Henares (Madrid),

MORENO CANTANO, ANTONIO CÉSAR (Coord.) (2011): El ocaso de la verdad. Propaganda y prensa exterior en la España franquista (1936-1945), Gijón, Trea.

MORENO CANTANO, ANTONIO CÉSAR (Coord.) (2012): Propagandistas y diplomáticos al servicio de Franco (1936-1945), Gijón, Trea.

PAYNE, STANLEY G. (1987): El régimen de Franco, 1936-1975, Madrid, Alianza, 1987.

PAYNE, STANLEY, G. (1997): Franco y José Antonio. El extraño caso del fascismo español, Barcelona, Planeta, 1997. 
PIZARROSO QUINTERO, ALEJANDRO (1990): Historia de la propaganda, Madrid, Eudema.

PIZARROSO QUINTERO, ALEJANDRO (2009): Diplomáticos, propagandistas y espías. Estados Unidos y España en la Segunda Guerra Mundial. Información y propaganda, Madrid, CSIC.

PORTERO, FLORENTINO Y PARDO, ROSA (1996): "La política exterior del régimen de Franco", en Carr, R. (Coord.) Historia de España. Menéndez Pidal. La época de Franco (1939-1975). Tomo XLI. Vol.I, Madrid, pp. 200-300.

PEREIRA, JUAN CARLOS (2010): “La Guerra Fría y su proyección sobre la política exterior del primer franquismo", en Forner, Salvador (Ed.): Coyuntura internacional y política española (1898-2004), Madrid, Biblioteca Nueva, pp. 119140.

RODRÍGUEZ JIMÉNEZ, JOSÉ LUIS (2000): Historia de Falange Española de las JONS, Madrid, Alianza.

SÁNCHEZ RECIO, GLICERIO (2005): La Internacional católica. "Pax Romana" en la política europea de posguerra, Madrid, Biblioteca Nueva/Universidad de Alicante.

SAZ CAMPOS, ISMAEL (2004): Fascismo y franquismo, Valencia, Universitat de Valencia.

SEVILLANO CALERO, FRANCISCO (1997): Propaganda y medios de comunicación en el franquismo (1936-1951), Alicante, Universidad de Alicante.

SEVILLANO CALERO, FRANCISCO (2002): "Propaganda y dirigismo cultural en los inicios del nuevo Estado", en Pasado y Memoria, 1, pp. 5-77.

SINOVA, JUSTINO (1989): La censura de prensa durante el franquismo, Madrid, Espasa.

SUÁREZ FERNÁNDEZ, LUIS (2001): Franco, crónica de un tiempo. Victoria frente al bloqueo, Madrid, Actas.

TERRÓN MONTERO, JAVIER (1981): La prensa en España durante el régimen de Franco, Madrid, CIS.

THÒMAS, JOAN MARÍA (2001): La Falange de Franco, Barcelona, Plaza y Janés.

TUSELL, JAVIER (1984): Franco y los católicos. La política interior española entre 1945 y 1957, Madrid, Alianza.

TUSELL, JAVIER (1993): Carrero Blanco. La eminencia gris del régimen de Franco. Madrid, Temas de Hoy. 
TUSELL, JAVIER (1995): Franco, España y la Il Guerra Mundial, Madrid, Temas de Hoy.

VIÑAS, ÁNGEL (Dir.) (2010): Al servicio de la República, Madrid, Marcial Pons. 